\title{
Female labour force participation and second birth rates in South Korea
}

\author{
Li Ma ${ }^{1}$
}

Published online: 25 March 2016

(C) The Author(s) 2016. This article is published with open access at Springerlink.com

\begin{abstract}
In recent decades, while female labour force participation rates in South Korea have increased, the country's total fertility rates have declined dramatically. This study explores the association between women's labour force participation and second birth rates in South Korea over the period 1980-2006. An event-history analysis is applied to longitudinal data from waves 1-10 of the Korea Labour and Income Panel Study. The study shows that post-birth labour force participation significantly reduced women's propensity for having a second child, whereas nonemployment after first birth was associated with an increased propensity. Women with highly educated husbands had a higher likelihood of enlarging the family. Further, the second birth trend in Korea fluctuated in tandem with the country's institutional and socio-economic development. The childbearing propensity of homemakers was especially sensitive to the business cycle.
\end{abstract}

Keywords Education - Labour force participation - Asian financial crisis $\cdot$ Second birth rates $\cdot$ South Korea

\section{Introduction}

Beginning in the 1960s, women's labour force participation rates have increased worldwide. Increases in women's education, women's growing preferences for nondomestic roles, men's gradual acknowledgement of women's employment, and growth in occupations that are frequently attractive to women are some of the myriad factors that have fostered this development (England and Farkas 1986). Over

Li Ma

li.ma@sociology.su.se

1 Demography Unit, Department of Sociology, Stockholm University, Universitetsvägen 10B, 10691 Stockholm, Sweden 
the same period, fertility has declined in many parts of the world. In the 1960s and the 1970s, the total fertility rates (TFRs) of many OECD countries dropped below replacement level.

Against this background, female labour force participation in South Korea (hereafter referred to as Korea) has increased modestly. Withdrawing from the labour market around childbearing ages has been a consistent trend among women (Ma 2014). Meanwhile, the country's fertility decline has been sharp. Korea's TFR was approximately six children per woman in 1960. By 2001, this value had decreased to 1.30, and Korea became one of the lowest low-fertility countries in the world. It has been argued that Korea's family planning program, which was initiated in 1962, stimulated this fertility plunge (Choe and Retherford 2009). Previous studies have addressed fertility developments in Korea. For example, Choe and Retherford (2009) present the development of parity progression ratios over the 1960-2007 period. Kye (2008a) examines the role of educational expansion in first marriage and first birth behavior. Ma (2013) demonstrates the relationship between women's employment and entry into motherhood.

Thus far, however, the relationship between Korean women's labour force participation and their likelihood of continued childbearing remains under-studied. We have little knowledge about how women's labour force participation is associated with their likelihood of having more than one child. Further, Korea went through the Asian financial crisis in the late 1990s. We are not clear about the higher-order fertility differences by couple's socio-economic status before and after the crisis. The present paper addresses these issues from an individual-level perspective. We focus on the transition to the second birth. The study period is from 1980 to 2006. Given that governmental limitation on family size was reaching its end in the late 1980s, and that Korea was hard hit by the outbreak of the Asian financial crisis in the late 1990s, second birth transitions before, during, and after these critical junctures will receive special attention.

This study makes contributions to demographic research in a few ways. First, although numerous studies have focused on higher-order childbearing, relevant knowledge regarding East Asian countries is limited. This study addresses this gap by investigating Korea. Second, Korea has experienced profound socio-economic and demographic change over the past few decades, with women becoming increasingly well educated and more active in the labour force. Previous research has shown that in Korea, women's employment stability propels entry into motherhood (Ma 2013). The present study enriches our understanding of the employment-fertility nexus by examining the association between employment and continued childbearing during a period of rapid social change. Third, Korea belongs to the group of East Asian developed societies in which welfare systems mainly rely on family principles. Thus, the current findings regarding how Korean women juggle work and family life likely resemble situations in other East Asian societies that have a similar welfare context. The findings may provide some inspiration for new policies to help facilitate the reconciliation of women's work and family obligations in East Asia. 


\section{Research framework: continued childbearing across contexts}

A large body of research has focused on mothers' continued childbearing. Women's education, their labour force participation, and family-related social policies have been the most widely studied factors. Differences across countries in socioeconomic and institutional settings, welfare regimes, and gender arrangements may account for differences in fertility patterns.

According to economic theories of opportunity costs, women suffer a loss of earnings when they take a break from the labour force for childbearing and childrearing (Becker 1981). To minimize this loss, women with high earning potential, such as the well-educated, tend to postpone or even forgo childbearing. Upon becoming mothers, the well-educated may concentrate their births over a short period of time to be able to resume their professional career as soon as possible after attaining their desired family size (Brewster and Rindfuss 2000).

Previous empirical research presents mixed findings concerning the roles of women's education and labour force participation in fertility. Evidence from the Nordic countries shows that women tend to postpone childbearing until they are well established in the labour market (Andersson 2000). Well-educated women proceed more quickly to second births than less-educated women (Hoem and Hoem 1989; Kravdal 1992, 2001; Oláh 2003). By contrast, a woman's educational level has little influence on her second and third birth propensity in some central European countries, such as Austria and West Germany; instead, the education of her partner plays an important role (Hoem et al. 2001; Kreyenfeld 2002; Prskawetz and Zagaglia 2005).

Resuming employment after entry into motherhood is one of many important transitions in a woman's life course. Women who undergo this transition must master juggling work and family life. A woman may be less willing to have another child when she is intensively involved in her employment. For example, employed mothers in Southern Europe have lower fertility rates than do housewives: the conventional model of men's employment combined with housewifery is related to higher second and higher-order births (Baizán 2007). Similarly, working mothers in Austria and West Germany are less likely to proceed to second and third births than are mothers who stay at home (Hoem et al. 2001; Prskawetz and Zagaglia 2005; Köppen 2006). According to Baizán (2007), women who follow the conventional model by leaving the labour market near their first birth (or even before their first birth) may be a group with particularly low labour market prospects; thus, parenthood and the role of housewife may be particularly attractive to these women. In contrast, in an investigation of women in Sweden who were involved in the labour force after their first birth, Hoem and Hoem (1989) reveal that full-time workers have slightly greater higher-order birth intensities than part-timers. It seems that the characteristics of women's jobs after childbirth do not appear to impact their higher-order birth rates in contexts in which sufficient public support is provided to dual-earner families with children.

Consequently, a better knowledge of the design of social policies in different contexts may help improve our understanding of the association between women's 
labour force participation and continued childbearing. In general, relatively high fertility may appear in countries in which social policies mitigate women's worklife role conflict (Brewster and Rindfuss 2000). In the Nordic countries with universalistic welfare regimes, social policies support women's labour force participation and promote gender equality. The effects of the opportunity to work flexible hours, paternal uptake of parental leave, and the availability of a public childcare system facilitate not only women's labour market involvement but also fertility (Andersson et al. 2004; Duvander and Andersson 2006; Duvander et al. 2010). By contrast, low fertility rates characterize those countries in Southern and Central Europe that encourage a traditional gendered division of work and care and in which the governments offer less policy support to allow women to reconcile work and family obligations (Brewster and Rindfuss 2000; Matysiak and Vignoli 2008). Under such contexts, having a first child for a woman often means committing oneself almost entirely to the family, as having children is likely to lead to a career break or the end of a career (Lutz et al. 2013).

The lower transition rates to second and third births among working mothers in Southern and Central Europe likely reflect a high level of gender equity incoherence (McDonald 2000). Nowadays, women have access to equal opportunities in education and the job market. However, if the bread-winner/care-giver family model still pertains, and if women receive insufficient policy support to combine work and family life, they often have to choose either work or family life. The gender equity incoherence reinforces the competition between work and family. Working women might reduce the number of children they would like to have, while those wanting more children might restrict their labour market engagement and shift to homemaking.

Economic uncertainty is also an important factor in explaining fertility development. It can be understood as an individual factor reflecting unemployment, having difficulties in the labour market or working on a fixed-term employment contract, or it can be conceptualized as an aggregate phenomenon such as an economic recession (Blossfeld and Hofmeister 2006; Sobotka et al. 2011; Kreyenfeld et al. 2012). In the face of an unstable economic situation, instead of childbearing, people might strengthen their ties to the labour force so as to reduce the risk of economic hardship (McDonald 2002). Fewer studies have addressed the effects of economic uncertainty on higher-order childbearing (Sobotka et al. 2011). Still, the link between unemployment and reduced second birth rates has been documented for England and Wales (De Cooman et al. 1987), Norway (Kravdal 2002) and Russia (Billingsley 2011). Empirical findings for other social settings might not necessarily be manifested in the specific context of Korea, a society that has simultaneously experienced increased female labour force participation, dramatic economic ups and downs, and fertility decline during the past few decades.

\section{The Korean context}

Figure 1 displays the TFRs of Korea compared with a few other selected OECD countries. Korea is one of the last OECD countries to undergo the fertility transition, but it stands out because its fertility decline is the sharpest. The initial fertility 


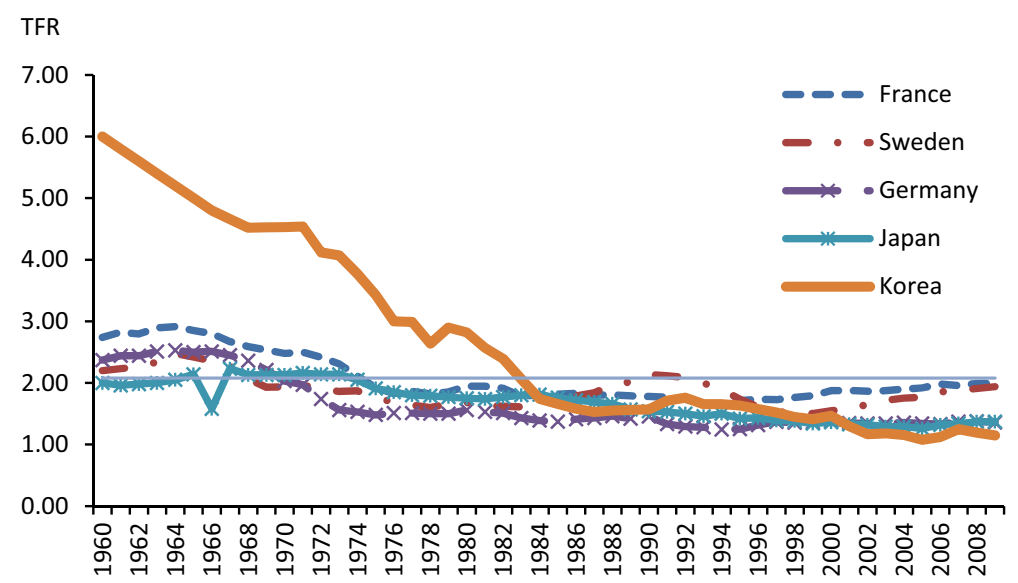

Fig. 1 Total fertility rates of Korea compared with a few other selected OECD countries. Source: OECD (2012a)

decline was arguably fuelled by the implementation of the family planning program, which was initiated in 1962 (Choe and Retherford 2009).

Dating back to the 1950s and 1960s, Korea experienced rapid population growth, high population density, high fertility, and a poorly developed industrial economy (Jones and Leete 2002). Like many other Asian countries, Korea viewed its growing population as an obstacle to economic development. In 1962, the government implemented a family planning program to control population growth (Rhee 2007). From the 1960s to the 1980s, great efforts were made to propagate the norm of small families (Cho 1996). During the late 1970s and the 1980s, the government encouraged reducing the typical family size to two children or fewer. Partly because the goals of reducing population growth and restricting family size had been achieved, the government relaxed its population control policy in the late 1980s (Choe and Retherford 2009). In the ensuing years, Korea's TFR modestly increased. In 1996, a new population policy with an emphasis on population quality and welfare was instituted, signifying the official abolition of the previous anti-natal policy (Cho 1996). However, the adjustment of the population policy did not halt Korea's long-term fertility decline. In 2001, Korea's TFR reached a low of 1.3, marking the onset of its "lowest-low" fertility era. Since then, it has remained below 1.3, anchoring Korea as one of the lowest low-fertility countries in the world.

Since the 1970s Korea has experienced dramatic economic development. By the mid-1990s, it had developed into one of the world's most industrialized societies. The country's economic success occurred in parallel with a remarkable increase in education, particularly among women (Jones 2011). Statistics show that the proportion of female high school graduates who advanced to higher education was only $20 \%$ in 1975. This rate increased to $81 \%$ in 2005 (Choe and Retherford 2009; Frejka et al. 2010). By 2010, $67 \%$ of women aged 25-34 had obtained tertiary education or above, compared to $63 \%$ of men (OECD 2012c). In parallel with attaining higher educational levels, women have tended to aspire to higher levels of 


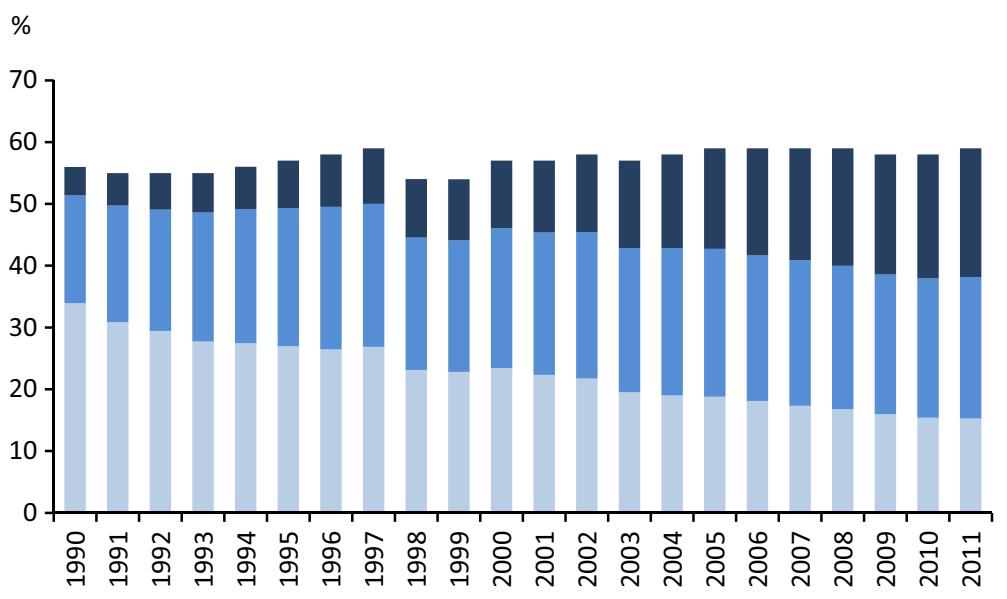

Middle school or below High school College or above

Fig. 2 Employment rates of women aged 20-49 by educational attainment, Korea, 1990-2011. Sources: OECD (2012b) and Korean Statistical Information Service (KOSIS) 2012

economic activity. Their labour force participation has been on the rise, but at a very slow pace. Figure 2 presents the employment rates and educational attainment of employed women aged 20-49 since 1990. Clearly, employed women have become better educated. In the early 1990s, only a small proportion of employed women had obtained an educational level of college or above. By 2011, nearly one-third of female labour force participants were college graduates.

Korea's economic growth occurred in the 1980s and early 1990s. Its OECD membership obtained in 1996 was a global acknowledgement of its economic miracle. Unexpectedly, the Asian financial crisis broke out in 1997, which brought a sudden rise in unemployment rates. Many life-long employment positions were converted into irregular ones. A lot of workers found themselves either in temporary jobs or unemployed (Kye 2008b). A sense of insecurity was felt in every corner of society. Although women's employment rates had been low, they still dropped notably during the period of downturn (see Fig. 2). It was not until 2002 that Korea's national economy started to revive.

Even though women's educational attainment reaches or even surpasses that of men in today's Korea, and women are actively involved in the labour market, Korea is still a society of familialism. Women have been considered the main caregivers of the household, and men the primary breadwinners. Women may work before marriage, but society expects them to quit jobs upon marriage. Raising children and performing household chores become their main responsibilities after marriage. Simply put, the level of gender equity incoherence is high (McDonald 2000). Over time, Korean women have adopted a distinct strategy to arrange their work-family life: labour market entry, labour market exit upon family formation and expansion, and labour market re-entry when the household has less need for them to be at home (Ma 2013). 
Korea's achievements in helping women combine work and family responsibilities have been modest (OECD 2011). The opportunity to work flexible hours is rare. The country's weekly average number of working hours is the highest among the OECD countries (OECD 2012b). Daycare services for children below the age of three have been insufficient. Paid maternity leave with job protection was not available until 2001. This lack of support in public policy makes it difficult for the average woman to avoid labour market withdrawal upon family formation (Anderson and Kohler 2013). Nonetheless, the outbreak of the Asian financial crisis in 1997 pushed women to hold on to their positions in the labour force. Homemakers became active labour force entrants during and after the crisis period, although the jobs they could get were overwhelmingly of lower status (Ma 2014). During the crisis, Korean men started to recognize the financial advantage of having a working wife (Anderson and Kohler 2013).

Despite public concern over low fertility and low female labour force participation in Korea, the link between women's labour force participation and higher-order fertility has not received sufficient attention. To reduce this knowledge gap, I will explore the following research questions.

1. What is the association between Korean women's labour force participation and second birth fertility? Who are more likely to have a second child, homemakers or working mothers? How do working mothers' labour market characteristics contribute to their second birth fertility? What is the role of husbands' socioeconomic status in women's second birth propensity?

2. How has Korea's second birth trend developed over time? How has the relationship between women's labour force participation and second birth fertility developed?

3. What are the implications of the findings?

\section{Data and methods}

The data that were used for analyses are from waves 1-10 of the Korea Labour and Income Panel Study (KLIPS), Korea's only labour-related panel survey, which was initiated by the Korea Labour Institute. The first wave was conducted in 1998 with an original sample of 5000 households in urban areas. Direct face-to-face interviews with the household reference person or spouse were undertaken to collect information on household members who were over 15 years of age. In special cases, other methods were used, such as self-administered questionnaires or telephone interviews.

In the first survey, both retrospective household data, such as demographic characteristics and changes in household composition, and individual socioeconomic data, such as work history and job characteristics, were collected. The survey was conducted annually to track changes in the characteristics of households' and individuals' economic and social activities. If an individual within a household turned 15 years old, or if an individual over 15 years of age joined a sampled household, he or she was included in the survey. New respondent data were 
collected regarding retrospective information. If some members of the households moved out and formed new families, the new household and its members were tracked as well. The most recent data for this study are from wave 10, which was conducted in 2007. The retention rates for waves 2-10 range from 76 to $88 \%$. The advantage of using KLIPS is that the rich longitudinal data on women's fertility history, work history (including the start and end time of each job spell), job features and husband's characteristics serve as valuable inputs to undertake an analysis of second birth fertility. The sample consists of people living in urban areas at the time of the interview, which limits its representativeness. However, respondents' childhood places of residence were controlled for in the analysis, which minimizes this drawback.

Event-history analysis was applied to observe the relationship between women's labour force participation and second birth fertility. This analytical method has the merit of allowing for observing the propensity for second births over time. Individuals who have not yet completed their reproductive career can also be observed.

Women who were married for the first time at the time of the first birth were followed. Each spell commenced from the month of the first birth; one-child mothers were tracked each month until a second birth occurred. When there was a disruption of the first marriage, the observation was censored. If there was no second birth, the observation ended at either the last interview time or age 45 . Because a woman's childbearing propensity is largely reduced after a long duration from the first birth, I also censored at 10 years after first birth. To better capture the link between women's post-birth work and their second birth decisions, I subtracted 9 months from the date of a reported second birth. For women who did not have a second child before the censoring time, I also pre-dated 9 months for consistency. Thus, the dependent variable in this study is the confirmed conception of a second live birth. In this paper, the terms "conception of second live birth" and "second birth" are used interchangeably. Of the 3323 one-child mothers who entered the observation window, 2231 proceeded to have a second child.

Table 1 presents the descriptive statistics of the covariates that were used for analysis. Time since first birth is the basic time factor. Calendar year is an important explanatory variable, as its estimation will demonstrate the period changes in second birth fertility. This variable was grouped into the following periods: 1980-1984, 1985-1989, 1990-1994, 1995-1999 and 2000-2006. Episodes before 1980 were left out because there were an insufficient number of cases for the analysis of these earlier years. The five-year grouping may appear arbitrary, but it aligns with Korea's socio-economic changes. The first two calendar periods cover the period when the policy concept of reducing family size was approaching its end. The second and third periods represent Korea's golden age of economic growth, while the last two periods during the late 1990s and early 2000s stand for the time when Korea suffered from financial disturbances.

Women's socio-economic status was measured in terms of education, labour force participation before first birth, and labour force participation after becoming a mother. Women's educational attainment (time-varying) was categorized as low, middle and high, representing below secondary, secondary, and tertiary education or 
Table 1 Descriptive statistics for covariates in the main effects models

\begin{tabular}{|c|c|c|c|}
\hline & Person-months & & $\begin{array}{l}\text { Second birth } \\
\text { conceptions }\end{array}$ \\
\hline \multicolumn{4}{|c|}{ Time since first birth (months) } \\
\hline $0-12$ & 25,574 & $19 \%$ & 501 \\
\hline $13-30$ & 38,339 & $29 \%$ & 1107 \\
\hline $31-60$ & 31,369 & $24 \%$ & 504 \\
\hline$>60$ & 35,880 & $27 \%$ & 119 \\
\hline \multicolumn{4}{|l|}{ Woman's age (years) } \\
\hline $15-24$ & 14,953 & $11 \%$ & 382 \\
\hline $25-29$ & 55,128 & $42 \%$ & 1276 \\
\hline $30-34$ & 41,771 & $32 \%$ & 525 \\
\hline $35-44$ & 19,310 & $15 \%$ & 48 \\
\hline \multicolumn{4}{|l|}{ Childhood residence } \\
\hline Seoul capital area & 34,493 & $26 \%$ & 575 \\
\hline Other metropolitan areas & 21,113 & $16 \%$ & 369 \\
\hline Other provinces & 75,556 & $58 \%$ & 1287 \\
\hline \multicolumn{4}{|l|}{ Gender of first child } \\
\hline Boy & 75,692 & $58 \%$ & 1124 \\
\hline Girl & 55,470 & $42 \%$ & 1107 \\
\hline \multicolumn{4}{|l|}{ Calendar years } \\
\hline $1980-84$ & 25,353 & $19 \%$ & 405 \\
\hline $1985-89$ & 30,614 & $23 \%$ & 431 \\
\hline 1990-94 & 25,046 & $19 \%$ & 481 \\
\hline 1995-99 & 20,501 & $16 \%$ & 436 \\
\hline $2000-06$ & 29,648 & $23 \%$ & 478 \\
\hline \multicolumn{4}{|l|}{ Education } \\
\hline Below secondary & 40,147 & $31 \%$ & 455 \\
\hline Secondary & 61,117 & $47 \%$ & 1231 \\
\hline Tertiary or above & 29,898 & $23 \%$ & 545 \\
\hline \multicolumn{4}{|c|}{ Labour force participation before first birth } \\
\hline Homemaker & 43,567 & $33 \%$ & 558 \\
\hline Employee & 87,595 & $67 \%$ & 1673 \\
\hline \multicolumn{4}{|c|}{ Labour force participation after first birth } \\
\hline Homemaker & 88,412 & $67 \%$ & 1649 \\
\hline Employee & 42,750 & $33 \%$ & 582 \\
\hline \multicolumn{4}{|l|}{ Husband's education } \\
\hline Below secondary & 29,592 & $23 \%$ & 333 \\
\hline Secondary & 57,323 & $44 \%$ & 1068 \\
\hline Tertiary or above & 44,247 & $34 \%$ & 830 \\
\hline Total & 131,162 & & 2231 \\
\hline
\end{tabular}

Source KLIPS, author's own calculations 
above, respectively. "Labour force participation before first birth" is a dummy variable that assesses how employment experience before motherhood contributes to second birth fertility. Women with no labour market experience prior to entry into motherhood were categorized as homemakers, whereas those who had employment experience were categorized as employees. "Labour force participation after first birth" is a crucial time-varying dummy variable that represents women's employment status after becoming mothers. During episodes when they stayed at home, women were categorized as homemakers. Beginning with the month in which they became involved in economic activity, they were considered as having postbirth work experience and categorized as employees.

To capture how womens' second birth propensity varied by their labour market characteristics after first birth, I expanded the category "employee" by the occupational status, income, and type of workplace (see "Appendix 1"). Based on the socio-economic index (SEI) defined by Ganzeboom and Treiman (1996), occupational status was stratified as low (e.g. elementary workers), middle (e.g. clerks and sales workers) or high (e.g. managers and professionals) (see "Appendix 2 "). Income was evenly divided into three percentile categories based on the ordered distribution of income values of one-child mothers in employment within each calendar year. Workplace was grouped into private sector, public sector (including state-owned enterprises), and other. Women who failed to report the above labour market characteristics were categorized as "missing" for the respective covariate.

Ignoring the husband's contribution to second births would cause bias when studying fertility in a context in which traditional gender norms prevail and the husband is considered to be the household's main breadwinner. In the current study, the husband's education served as a proxy for his socio-economic status. Accordingly, it is grouped in the same way as woman's educational attainment.

A number of variables were controlled for, including women's current age, childhood residence, and the first child's gender. Childhood residence (residence at age 14) was grouped into the following three categories: the Seoul National Capital Area (including Seoul, Incheon, and Gyeonggi-do), other metropolitan areas (including Busan, Daegu, Daejeon, Gwangju, and Ulsan), and other provinces (South Korea's other nine provinces). The gender of the first child was included as an important indicator of continued childbearing in a society with a long history of son preference.

\section{Results of main effects models}

Table 2 presents the hazard ratios of second birth propensity from the main effects models. Model 1 involved only woman's age, childhood residence, first child's gender and calendar years. Models 2-5 added education, labour force participation before first birth, labour force participation after first birth, and husband's education in a stepwise manner so that we can clearly observe how women's socioeconomic characteristics and husbands' socio-economic status contributed to the observed patterns and to second birth fertility. 


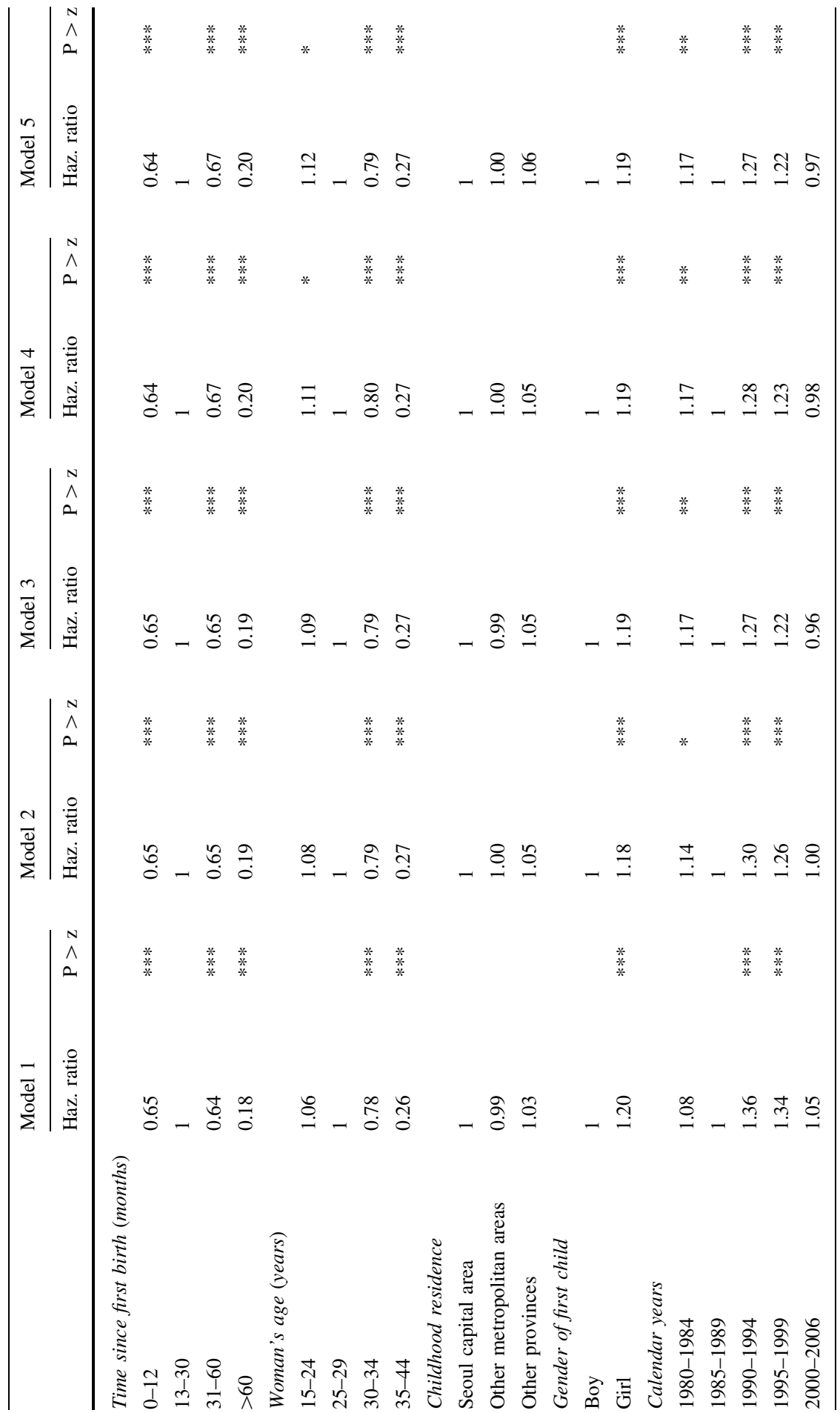




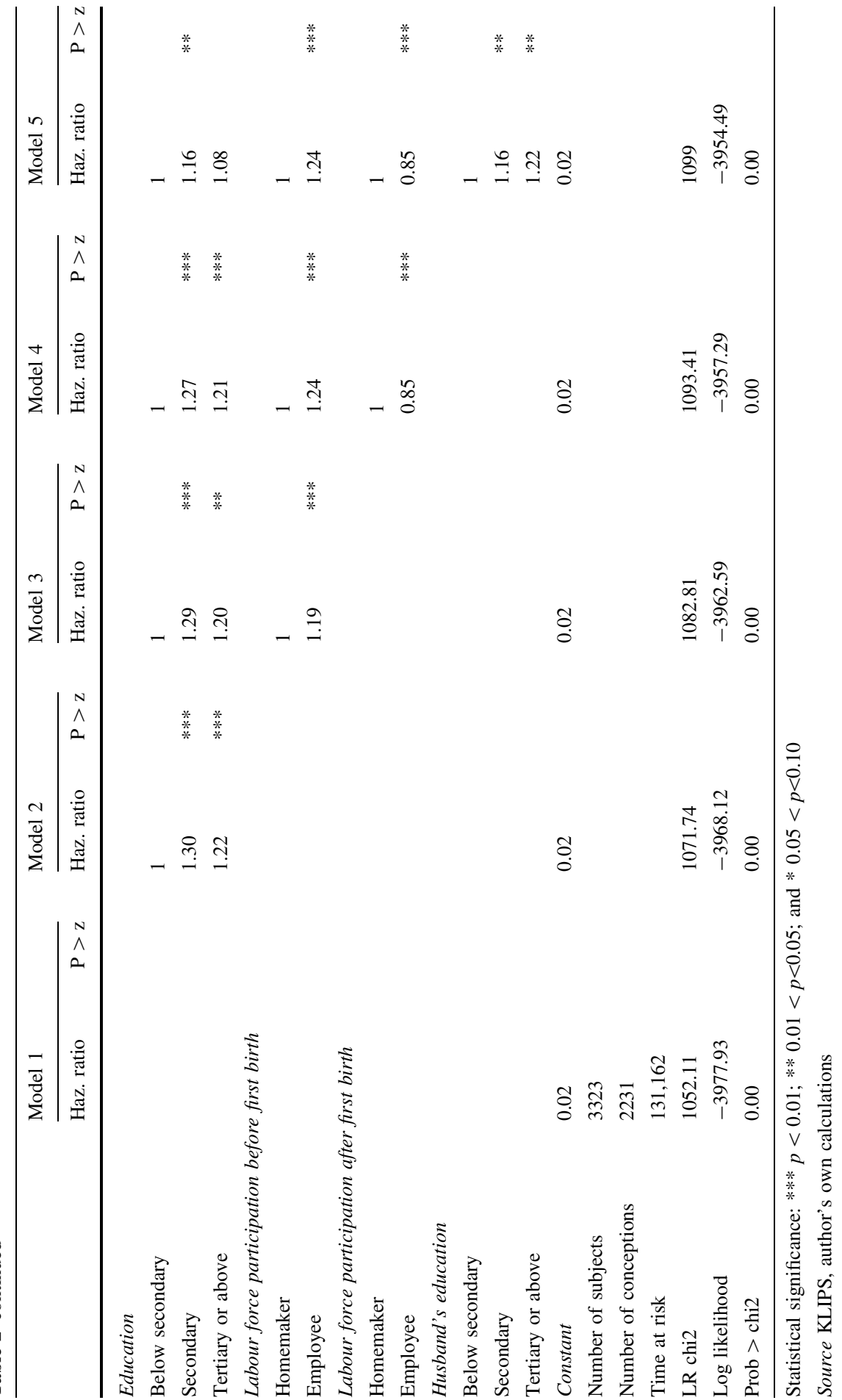


The estimates for calendar period demonstrate that the second birth trend fluctuated over the study period (see Table 2). Relative to the second birth rates for the period 1985-1989, those for the first half of the 1980s and for the entirety of the 1990s were significantly higher. To capture how the trend developed in more detail, I expanded Model 5 by replacing calendar periods with single years while standardizing for all other variables; the results are presented in "Appendix 3". We can see that during the 1980s, the second birth trend headed toward its nadir, with birth rates decreasing notably. From the late 1980s, a clear reversal emerged. In the early 1990s, second births returned to the level of 1980. However, the reversal was only temporary. From the late 1990s onwards, second births declined again. Fluctuations in second births were in parallel with Korea's major institutional and socio-economic changes. During the 1980s when the small family was advocated in the family planning program, second births declined. The trend reversal from the late 1980s through the mid-1990s corresponded with the country's golden age of economic growth and the official abandonment of the family planning program. However, the social insecurity generated by the outbreak of the financial crisis in the late 1990s seems to have led families to opt for smaller family sizes again.

The estimation for women's education shows that women with secondary educational attainment were more likely to have an additional child than women with other educational levels. A significant change occurred when the husband's education was accounted for. Specifically, the difference across women's own educational levels was significantly reduced. Estimates of the husband's educational attainment demonstrate that the likelihood that a woman will have a second child increases as the educational achievement of her husband increases. The results indicate that a woman's second birth propensity in Korea substantially depends on her husband's education and his potential for accumulating the necessary economic resources for a large family.

Our estimations for women's labour force participation before and after first birth reveal some compelling results. Women had a significantly higher second birth rate if they had labour force experience prior to the first birth than if they did not (Models 4 and 5). This finding underlines the importance of having a secure social position before entering parenthood in Korean society.

In comparison, women who were engaged in postpartum economic activity had significantly lower second birth propensity than homemakers. The result can be explained in several ways. First, the high level of gender equity incoherence in the social and family spheres of Korean society restricts working mothers' fertility. Juggling the demands of job duties and household chores is difficult. Those who resumed employment were therefore less likely to expand their family size. Second, the option of entering or resuming employment or staying at home reflects women's value orientation. Those who decided for homemaking might be more familyoriented and keen on their role as a mother. In contrast, women who resumed employment quickly after their first birth are likely to be more career-oriented and more satisfied with having only one child. Resuming employment might be their strategy of reducing the potential career opportunity cost. Further, it deserves mention that some mothers might engage themselves in irregular jobs in order to accumulate economic resources to support their children's education, while others 
might resume employment as their husband's earning power runs low. Evidently, a change in labour market activity between pre- and post-partum periods signals a woman's intention to focus more strongly on one sphere of life than the other.

\section{Results of interaction models}

To explore how different factors may influence women's second birth fertility in combination with each other, several interaction terms vis-à-vis couple's socioeconomic status and calendar periods were estimated, while all other factors were controlled for. Figure 3 demonstrates that women who were employed before childbearing but shifted to homemaking afterwards had significantly higher second birth rates than other categories of mothers. This highlights that women who were established in the labour market but opted for home-making after first birth were the ones who were most motivated to have another child and build a larger family.

There is no interaction effect between husband's education and woman's labour force participation after first birth (not shown). The amplifying effect of husband's educational attainment is observed for both homemakers and working mothers. This suggests that if the husband has a high earning capacity, both homemakers and working mothers are more likely to have a second birth.

The interaction term between the calendar period and women's employment activity after first birth warrants attention (see Fig. 4). During the study's observation period, the homemakers were consistently more likely to have a second child than were one-child mothers in the labour force. However, the second birth trends for homemakers and mothers in the labour force developed in slightly different ways over time. Births among both groups decreased in the 1980s. Beginning in the late 1980s, the trend for homemakers increased sharply. However,

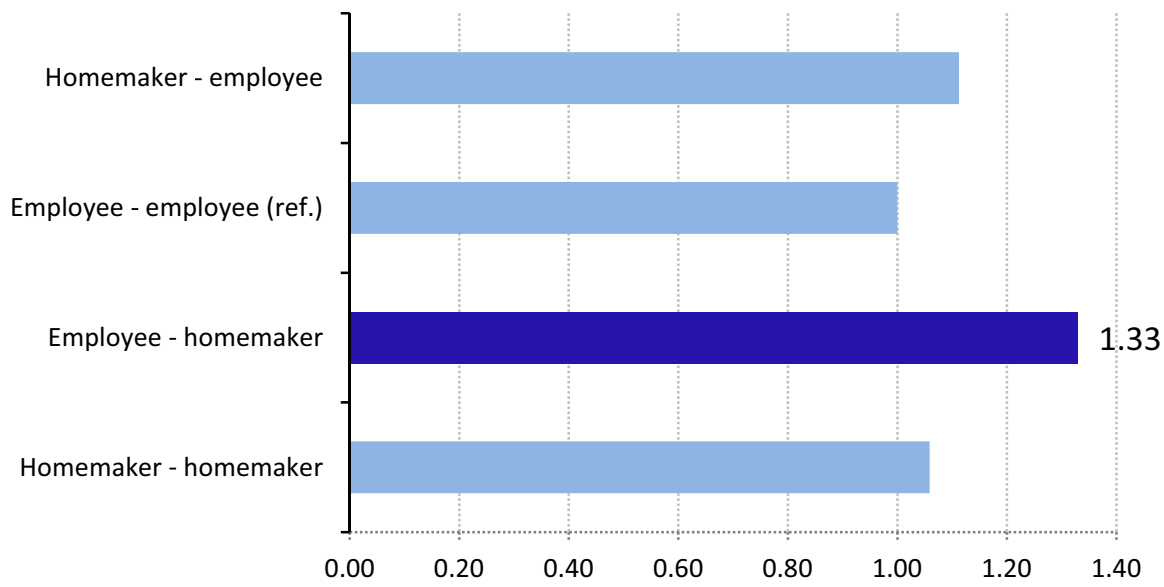

Fig. 3 Interactive effect of women's labour force participation before and after first birth, second births in Korea, 1980-2006, standardized for other control variables (reference category: Employee-employee). Source: KLIPS, author's own calculations 


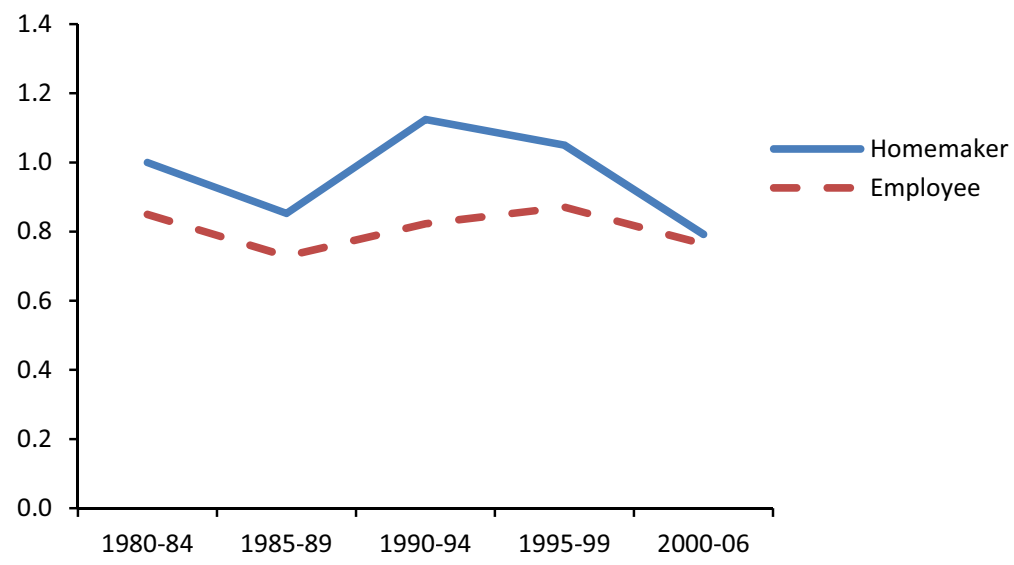

Fig. 4 Interactive effect of women's labour force participation after first birth and calendar periods, second births in Korea, 1980-2006, standardized for other control variables (reference category: Homemaker after first birth, 1980-84). Source: KLIPS, author's own calculations

this reversal was temporary; the trend declined substantially from the late 1990s onwards. The second birth trend for employed mothers was also reversed from the late 1980s, but at a more moderate pace. The difference between the two groups became smaller towards the end of our observation period. These results seem to suggest that the second birth fertility of homemakers is somewhat more sensitive to contextual changes. During the peak of Korea's economic growth and the reversal in family planning policy in the late 1980s to the mid-1990s, homemakers were at the forefront of resuming the pattern of having a second child. At the outbreak of the Asian financial crisis in the late 1990s, they were instead in the lead in restricting family size. Previous research shows that homemakers were eager to rush back to the labour market during and after the crisis, striving to improve their households' precarious economic situation (Ma 2014). Their labour market participation during and after the crisis periods further reduced their likelihood of having a second child.

Additional interaction models were estimated to check whether privileged women (those with high educational attainment) might shorten their birth intervals in order to resume employment more quickly after they achieve their desired fertility. However, no acceleration of second births was observed for these women. I specified other interaction models for evidence of further interactive effects. These results are consistent with the multiplicative findings of the main effects model and thus are not presented in this paper.

\section{Results of extended model}

To determine the association between women's labour market characteristics after first birth and their second birth propensity, I expanded Model 5 in Table 2 into three additional models (see Models 5A-5C in Table 3). Specifically, I expanded 
Table 3 Relative risks of second births by female labour market characteristics after first birth, standardized for other covariates (results from models expanded from Model 5)

\begin{tabular}{llll}
\hline & Haz. ratio & $p>\mathrm{z}$ & Log likelihood \\
\hline $\begin{array}{l}\text { Model 5A } \\
\text { Occupational status (first job after first birth) }\end{array}$ & & & -3952.89 \\
Homemaker & 1.36 & $* * *$ & \\
SEI $<40$ & 1 & & \\
SEI 40-50 & 1.17 & $*$ & \\
SEI $>50$ & 1.26 & & \\
Missing * & 1.24 & \\
Model 5B & & & \\
Income (first job after first birth) & & & \\
Homemaker & 1.22 & \\
Low & 1 & \\
Middle & 1.12 & \\
High & 1.07 & \\
Missing & 1.01 & \\
Model 5C & & \\
Workplace (first job after first birth) & & \\
Homemaker & 1.15 & \\
Private & 1 & \\
Public & 1.17 & \\
Other & 0.54 & \\
Missing & 0.93 & \\
\hline
\end{tabular}

Statistical significance: $* * * p<0.01 ; * * 0.01<p<0.05$; and $* 0.05<p<0.10$

The estimation of missing values in "occupational status" is not statistically significant because of the limited number of cases in this category

Source KLIPS, author's own calculations

working mothers' employment status with further details regarding the occupational status, income, and type of workplace of their first postpartum job while standardizing all other variables in Model 5. The effects of other covariates resemble those presented in Model 5, and are thus not presented again.

Findings of the expanded models demonstrate some new patterns. Among the employed mothers, those holding a high occupational status had a significantly higher likelihood than others of continued childbearing. The estimates for other job characteristics show that women with middle or high incomes, as well as women employed in the public sector, had relatively higher second birth rates, though these results are not significant. Together, they still imply that for mothers who are active in the labour market, employment security and earning potential are important to second birth propensity.

Another finding, though not the focus of this study, is notable: "Appendix 4" shows that in the 1980s, women who bore a girl for the first birth had a significantly 
higher rate of continued childbearing than did women who had a boy. However, this difference was substantially reduced over time. By the end of the observation period, the difference was practically nonexistent. The result reveals that the son preference, which was once strong and a driving force for a family's continued childbearing, has lost its power.

\section{Conclusion}

Korea has experienced dramatic economic development and fertility decline since the 1960s. Its family planning program was arguably a primary driving force behind the initial fertility decline. Korea's social organization is gender based, though women's educational attainment has reached and recently exceeded that of men. Men assume primary responsibility for providing economic support to the household, whereas women are expected to exit the labour force and provide care at home upon family formation and expansion. The outbreak of the Asian financial crisis in the late 1990s challenged this traditional family model: women increasingly aimed for paid work to mitigate precarious family economics; men started to perceive the advantage of having a working wife.

The present study explores women's transition to second childbearing against this background. It explores how women's education and labour force participation are linked to their second birth fertility, how husband's socio-economic status (measured as educational attainment) contributes to family expansion, and how these relationships have developed over time. Event-history analyses were applied to longitudinal survey data. Main effects models, interactive models and expanded models were estimated.

Our estimations from the main effects model show that women with secondary educational attainment are more likely than others to transition to a second birth. When husband's education is taken into consideration, the differences across women's educational attainment becomes smaller. Those with a highly educated husband are more likely to have a second child. This points to the important role of husbands' earning potential in family expansion. Women's labour force participation before first birth is positively linked to their second birth fertility, suggesting that women are inclined to make the transition to family life after realizing their occupational goals and collecting the economic resources to build a family. By contrast, women's employment engagement after first birth acts as a deterrent against more children. One-child mothers in the labour force have a significantly lower second birth propensity than homemakers.

In addition, the estimates for calendar years demonstrate that the second birth trend fluctuates in tandem with Korea's institutional and socio-economic changes. During the 1980s when small families were still encouraged, the second birth trend was in decline. From the late 1980s and during the mid-1990s when Korea underwent its golden age of economic growth and small families were no longer encouraged, the trend reversed. However, the reversal was only temporary. During the late 1990s when the smooth process of socio-economic development was interrupted by the unexpected Asian financial crisis, the birth trend declined anew and then levelled until the end of the observation time. 
Our interaction models reveal more in-depth results. Women who were employed before first birth but opted for home-making after becoming mothers were the ones most likely to have a second child. During the entire observation period, homemakers were at the forefront of second birth fertility. Further, their second birth fertility seems more sensitive to contextual changes, in particular the business cycle.

In summary, the findings for the Korean context consolidate existing knowledge that in a conservative society where the breadwinner-caregiver family model persists, the husband's potential for collecting economic resources plays an essential role in family expansion. These findings resemble those for Southern European countries and Germany-speaking countries, in which traditional gender norms prevail and the policy support for the reconciliation of work and family is insufficient. In these contexts the maintenance of the two-child norm is substantially dependent on the husband's potential to aggregate economic resources. A key contribution of the present study is that it demonstrates how Korea's second birth fertility develops in tandem with institutional and socio-economic changes. In particular, during the economic downturn and its aftermath, almost all women restricted themselves from having an additional child.

Surprisingly, some findings are rather similar to those for Nordic societies where gender equity is pursued, public support to help women combine work and family is more developed, and fertility is relatively high. Our expanded models show that among working mothers in Korea, those with better labour market standing have slightly higher second birth rates than others. This similarity of findings for completely different societies reflects the relative importance of employment security and earning potential for higher order births, regardless of institutional setting. Meanwhile, it provides an indication that if the government makes more efforts to improve working women's employment security, and assists women to better combine work and family life, Korea's challenges of low female labour force participation and low fertility might gradually ease.

Since 2006, the Korean government has taken strides toward creating a more family-friendly environment, and welfare expansions may have improved work-life compatibility. However, the available data for analysis only extend to 2007. To obtain a more updated picture of recent developments in Korea, further research that is based on more recent data is required. It is hoped that the findings of this study serve the purpose of stimulating the ongoing debate in East Asia about how to promote work-life balance policies.

Acknowledgments I would like to express my greatest gratitude to Gunnar Andersson and Gerda Neyer for their constant advice and valuable comments during the process of this study. Great thanks also go to Hyun Song Lee, with whom I had an in-depth discussion about the findings of this study. Earlier versions of the manuscript benefited from comments received at the XXVII IUSSP International Population Conference in August 2013, Busan, Korea. Special thanks go to Anni Li for her assistance in designing the figures.

Open Access This article is distributed under the terms of the Creative Commons Attribution 4.0 International License (http://creativecommons.org/licenses/by/4.0/), which permits unrestricted use, distribution, and reproduction in any medium, provided you give appropriate credit to the original author(s) and the source, provide a link to the Creative Commons license, and indicate if changes were made. 


\section{Appendix 1}

See Table 4.

Table 4 Descriptive statistics of covariates for the extended main effects models

\begin{tabular}{lccc}
\hline & Person-months & & Conceptions of 2nd birth \\
\hline Occupational status (first job after first birth) & & & \\
Homemaker & 88,412 & $67 \%$ & 1649 \\
SEI $<40$ & 11,611 & $9 \%$ & 110 \\
SEI 40-50 & 21,502 & $16 \%$ & 305 \\
SEI $>$ 50 & 7786 & $6 \%$ & 144 \\
Missing & 1851 & $1 \%$ & 23 \\
Income (first job after first birth) & & & \\
Homemaker & 88,412 & $67 \%$ & 1649 \\
Low & 4577 & $3 \%$ & 64 \\
Middle & 5642 & $4 \%$ & 107 \\
High & 6142 & $5 \%$ & 104 \\
Missing & 26,389 & $20 \%$ & 307 \\
Workplace (first job after first birth) & & & \\
Homemaker & 88,412 & $67 \%$ & 1649 \\
Private & 9188 & $7 \%$ & 147 \\
Public & 5329 & $4 \%$ & 114 \\
Other & 1012 & $1 \%$ & 7 \\
Missing & 27,221 & $21 \%$ & 314 \\
Total & 131,162 & & 2231 \\
\hline
\end{tabular}

Source KLIPS, author's own calculations

\section{Appendix 2}

See Table 5.

Table 5 Korean Standard Classification of Occupations (KSCO) and corresponding socio-economic index (SEI) scores based on Ganzeboom and Treiman (1996)

\begin{tabular}{lc}
\hline KSCO & SEI score \\
\hline 1. Managers & 55 \\
2. Professionals and related workers & 70 \\
3. Clerks & 45 \\
4. Service workers & 40 \\
5. Sales workers & 40 \\
6. Skilled agricultural, forestry, and fisheries workers & 23 \\
\hline
\end{tabular}


Table 5 continued

$\mathrm{KSCO}$

SEI score

7. Craft and related trade workers

8. Equipment, machine operating and assembly workers

9. Elementary workers

\section{Appendix 3}

See Fig. 5.

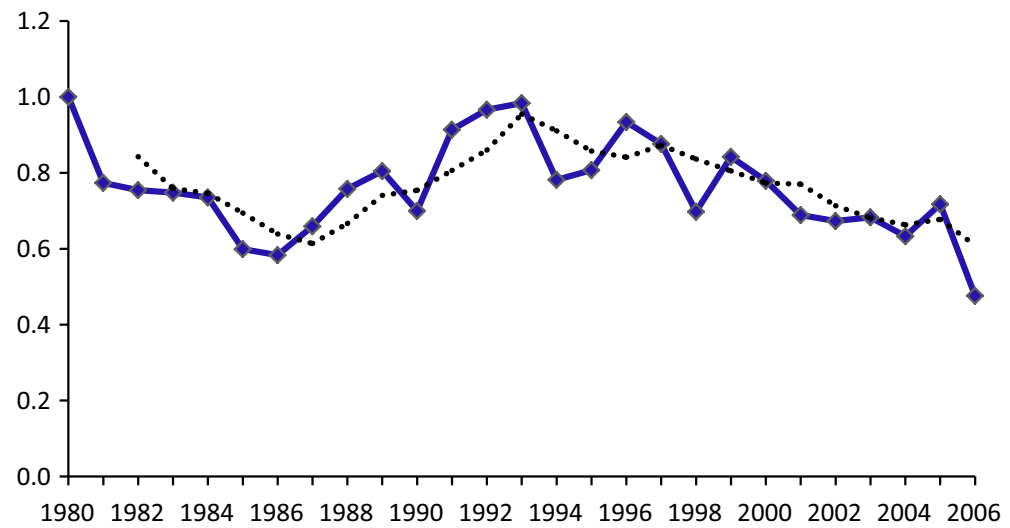

Fig. 5 Relative risks of second births by single years (together with moving average of 3 years) for onechild mothers in Korea, 1980-2006, standardized for other control variables (reference category: 1980). Source: KLIPS, author's own calculations 


\section{Appendix 4}

See Fig. 6.

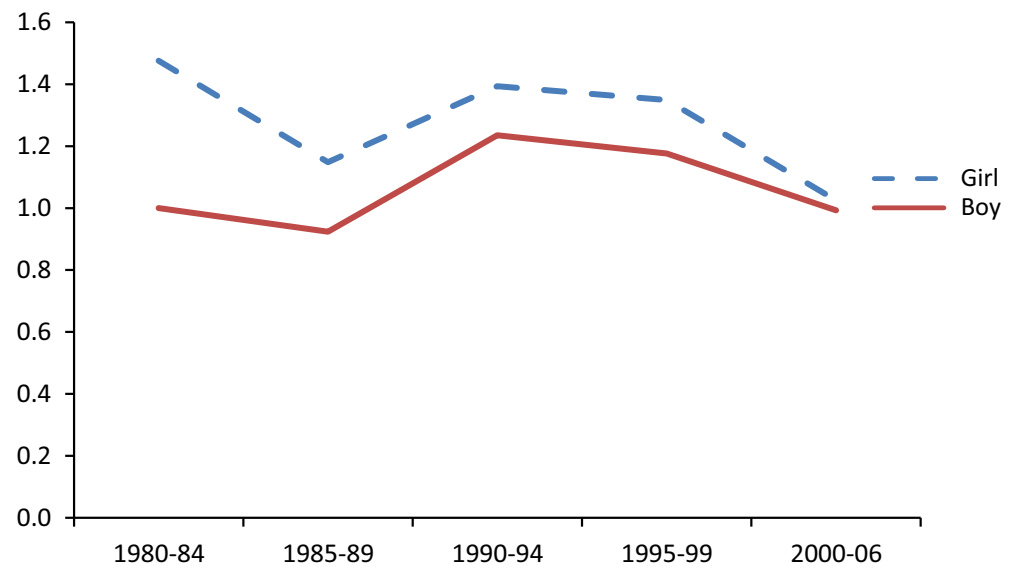

Fig. 6 Interactive effect of gender of first child and calendar periods, second births in Korea, 1980-2006, standardized for other control variables (reference category: Boy, 1980-1984). Source: KLIPS, author's own calculations

\section{References}

Anderson, T. M., \& Kohler, H.-P. (2013). Education fever and the East Asian fertility puzzle: A case study of low fertility in South Korea. Asian Population Studies, 9(2), 196-215.

Andersson, G. (2000). The impact of labour-force participation on childbearing behaviour: Pro-cyclical fertility in Sweden during the 1980s and the 1990s. European Journal of Population, 16, 293-333.

Andersson, G., Duvander, A.-Z., \& Hank, K. (2004). Do child-care characteristics influence continued childbearing in Sweden? An investigation of the quantity, quality, and price dimension. Journal of European Social Policy, 14(4), 407-418.

Baizán, P. (2007). The impact of labour market status on second and higher-order births. A comparative analysis based on the European Community household panel. In G. Esping-Andersen (Ed.), Family formation and family dilemmas in contemporary Europe (pp. 93-127). Madrid: Fundación BBVA.

Becker, G. S. (1981). A treatise on the family. Cambridge: Harvard University Press.

Billingsley, S. (2011). Economic crisis and recovery: Changes in second birth rates within occupational classes and educational groups. Demographic Research, 24(16), 375-406.

Blossfeld, H.-P., \& Hofmeister, H. (2006). Globalization, uncertainty and women's careers: An international comparison. Cheltenham: Edward Elgar Publishing.

Brewster, K. L., \& Rindfuss, R. R. (2000). Fertility and women's employment in industrialized nations. Annual Review of Sociology, 26, 271-296.

Cho, N. (1996). Achievements and challenges of the population policy development in Korea. Hacheong Yeon: Korea Institute for Health and Social Affairs.

Choe, M. K., \& Retherford, R. D. (2009). The contribution of education to South Korea's fertility decline to 'Lowest-low' level. Asian Population Studies, 5(3), 267-288.

De Cooman, E., Ermisch, J., \& Joshi, H. (1987). The next birth and the labour market: A dynamic model of births in England and Wales. Population Studies, 41(2), 237-268.

Duvander, A.-Z., \& Andersson, G. (2006). Gender equality and fertility in Sweden: A study on the impact of the father's uptake of parental leave on continued childbearing. Marriage and Family Review, 39, $121-142$. 
Duvander, A.-Z., Lappegård, T., \& Andersson, G. (2010). Family policy and fertility: Fathers' and mothers' use of parental leave and continued childbearing in Norway and Sweden. Journal of European Social Policy, 20(1), 45-57.

England, P., \& Farkas, G. (1986). Households, employment and gender: A social. Economic and Demographic View: Aldine.

Frejka, T., Jones, G., \& Sardon, J.-P. (2010). East Asian childbearing patterns and policy developments. Population and Development Review, 36(3), 579-606.

Ganzeboom, H. B. G., \& Treiman, D. J. (1996). Internationally comparable measures of occupational status for the 1988 International Standard Classification of Occupations. Social Science Research, 25(3), 201-239.

Hoem, B., \& Hoem, J. M. (1989). The impact of women's employment on second and third births in Modern Sweden. Population Studies: A Journal of Demography, 43(1), 47-67.

Hoem, J. M., Prskawetz, A., \& Neyer, G. (2001). Autonomy or conservative adjustment? The effect of public policies and educational attainment on third births in Austria. Population Studies, 55(3), 249-261.

Jones, G. (2011). Recent fertility trends, policy responses and fertility prospects in low fertility countries of East and Southeast Asia. Population Division Expert Paper 5. United Nations Department of Economic and Social Affairs.

Jones, G., \& Leete, R. (2002). Asia's family planning programs as low fertility is attained. Studies in Family Planning, 33(1), 114-126.

Köppen, K. (2006). Second births in West Germany and France. Demographic Research, 14(14), 295-330.

Kravdal, Ø. (1992). The emergence of a positive relation between education and third birth rates in Norway with supportive evidence from the United States. Population Studies, 46(3), 459-475.

Kravdal, Ø. (2001). The high fertility of college educated women in Norway: An artefact of the separate modeling of each parity transition. Demographic Research, 5(6), 187-216.

Kravdal, Ø. (2002). The impact of individual and aggregate unemployment on fertility in Norway. Demographic Research, 6(19), 263-294.

Kreyenfeld, M. (2002). Time-squeeze, partner effect or self-selection? An investigation into the positive effect of women's education on second birth risks in West Germany. Demographic Research, 7(2), $15-48$.

Kreyenfeld, M., Andersson, G., \& Pailhé, A. (2012). Economic uncertainty and family dynamics in Europe: Introduction. Demographic Research, 27(28), 835-852.

Kye, B. (2008a). Delay in first marriage and first childbearing in Korea: Trends in educational differentials. California Center for Population Research Working Paper Series, UC Los Angeles.

Kye, B. (2008b). Internal labour markets and the effects of structural change: Job mobility in Korean labour markets between 1998 and 2000. Research in Social Stratification and Mobility, 26, 15-27.

Lutz, K., Boehnke, M., Huinink, J., \& Tophoven, S. (2013). Female employment, reconciliation policies and childbearing intentions in East and West Germany. In L. S. Oláh \& E. Frątczak (Eds.), Childbearing, women's employment and work-life balance policies in contemporary Europe (pp. 97-134). Basingstoke: Palgrave Macmillan.

Ma, L. (2013). Employment and motherhood entry in South Korea, 1978-2006. Population, 68(3), $419-446$.

Ma, L. (2014). Economic crisis and women's labour force return after childbirth: Evidence from South Korea. Demographic Research, 31(18), 511-552.

Matysiak, A., \& Vignoli, D. (2008). Fertility and women's employment: A meta-analysis. European Journal of Population, 24(4), 363-384.

McDonald, P. (2000). Gender equity in theories of fertility transition. Population and Development Review, 26(3), 427-439.

McDonald, P. (2002). Sustaining fertility through public policy: The range of options. Population, 57(3), 417-446.

OECD. (2011). Dong better for families. OECD.

OECD. (2012a). OECD family database. Paris: OECD.

OECD. (2012b). OECD employment database. Paris: OECD.

OECD. (2012c). OECD education database. Paris: OECD.

Oláh, L. Sz. (2003). Gendering fertility: second births in Sweden and Hungary. Population Research and Policy Review, 22(2), 171-200. 
Prskawetz, A., \& Zagaglia, B. (2005). Second births in Austria. Vienna Yearbook of Population Research, 3, 143-170.

Rhee, O. (2007). Childcare policy in Korea: Current status and major issues. International Journal of Child Care and Education Policy, 1(1), 59-72.

Sobotka, T., Skirbekk, V., \& Philipov, D. (2011). Economic recession and fertility in the developed world. Population and Development Review, 37(2), 267-306. 